\title{
Molecular characterization and tissue transcription profile analyses of three novel pig genes - NDP, CLN3 and NCF1*
}

\author{
G.P. Wang ${ }^{1}$, Y.Y. He ${ }^{1}$, S.F. Hu${ }^{1}$, W. Liu ${ }^{1}$ and G.Y. Liu ${ }^{2,3}$ \\ ${ }^{1}$ Hunan Agricultural University, Veterinary Faculty \\ Changsha, 410128, P.R. China \\ ${ }^{2} Y u n n a n$ Agricultural University, \\ Key Laboratory of Animal Nutrition and Feed of Yunnan Province \\ Kunming, 650201, P.R. China
}

(Received 19 May 2008; revised version 17 October 2008; accepted 23 January 2009)

\begin{abstract}
The complete coding sequences of three porcine genes - NDP, CLN3 and NCF1 - were amplified using the reverse transcriptase polymerase chain reaction (RT-PCR) based on the conserved sequence information of the human, mouse, and referenced highly homologues pig ESTs. The sequence analyses of these three genes revealed that porcine NDP gene encodes a protein of 133 amino acids which has high homology with the Norrie disease protein homolog (NDP) of four species: bovine (98\%) human (96\%), crab-eating macaque $(96 \%)$ and mouse $(95 \%)$. The porcine CLN3 gene encodes a protein of 438 amino acids which has high homology with the ceroid-lipofuscinosis, neuronal 3 (CLN3) of four species: human (90\%), crab-eating macaque $(90 \%)$, dog $(89 \%)$ and mouse $(83 \%)$. The porcine NCF1 gene encodes a protein of 392 amino acids that has high homology with the neutrophil cytosolic factor $1(\mathrm{NCF} 1)$ of three species: bovine $(87 \%)$, human $(82 \%)$ and mouse (79\%). Phylogenetic tree analysis revealed that the porcine NDP and NCF1 has closer genetic relationships with the bovine NDP and NCF1, but the porcine CLN3 has a closer genetic relationship with the CLN3 of human and crab-eating macaque. The tissue transcription profile analyses indicated that pig CLN3 and NCF1 genes were generally expressed in most of tissues, pig NDP gene was expressed in muscle, spleen, brain, lung but not expressed in kidney, liver, backfat and pancreas. These data serve as a foundation for further research on these three genes which have been associated with human disease.
\end{abstract}

KEY WORDS: pig, NDP, CLN3, NCF1, tissue transcription profile

\footnotetext{
* Supported by Grants from the National Natural Science Foundation of China (No. 3080010)

${ }^{3}$ Corresponding author: e-mail: liuyg4567@163.com
} 


\section{INTRODUCTION}

Norrie disease protein homologue (NDP) is an important gene identified as harbouring mutations that results in Norrie disease. Norrie disease (ND) is a rare X-linked recessive disorder characterized by congenital blindness and in some cases, mental retardation and deafness (Battinelli et al., 1996; Lev et al., 2007). Recently research indicated that the homozygous mutation of NDP is also related to foetal loss in Norrie disease mice (Luhmann et al., 2005). Ceroidlipofuscinosis, neuronal 3 (CLN3) is another important gene which encodes a protein that is involved in lysosomal function. Mutations in this, as well as other neuronal ceroid-lipofuscinosis (CLN) genes, cause neurodegenerative diseases commonly known as Batten disease (Adams et al., 2007; Eliason et al., 2007). Neutrophil cytosolic factor 1 (NCF1) is a $47 \mathrm{kDa}$ cytosolic subunit of neutrophil NADPH oxidase. This oxidase is a multicomponent enzyme that is activated to produce superoxide anion. Mutations in this gene have been identified to be associated with chronic granulomatous disease (El Kares et al., 2006; Roos et al., 2006; Köker et al., 2007).

Based on these described above, these three genes are associated with three important mutation diseases of human. The three diseases have also been reported in the mouse (Kishida et al., 2006; Kovács and Pearce, 2006; Wollmann et al., 2006). Although these diseases have not been documented in the pig, as same as mammalian, these inherited diseases also maybe occur in pigs for the pig has been used as a major mammalian model for human studies because of the similarity in size and physiology, and in organ development and disease progression (Lunney et al., 2007; Rothschild and Plastow, 2008). To date, the porcine NDP, CLN3 and NCF1 genes have not been cloned. Cloning and sequence analysis of these porcine genes would be an important step in establishing whether the suitability of the pig as a model for studying these disease.

Comparative genomics research has revealed that virtually all $(99 \%)$ of the protein-coding genes in humans align with homologues in mouse, and over $80 \%$ are clear 1:1 orthologs (Hardison, 2003). This extensive conservation in proteincoding regions implies that this conservation of protein-coding sequences may be expected in different mammals including pigs. With the development of modern bioinformatics, many more specific databases such as NCBI pig EST database were established. These along with different convenient analysis tools make it much easier to find the pig EST sequences highly homologues to some proteincoding sequences of the mouse and human. These tools also make it easer to isolate the encoding regions of some pig genes based on the conserved proteincoding sequence information of other mammals and the highly homologues EST sequence information. 
The objective of this study was to clone and analyse the coding sequences of porcine NDP, CLN3 and NCF1 genes, and determine their tissue transcription profiles. The data obtained will serve as a basis for understand these porcine genes.

\section{MATERIAL AND METHODS}

Samples collection, RNA extraction and first-strand cDNA synthesis

The tissue samples of brain, kidney, liver, muscle, backfat, lung, spleen and pancreas, were obtained from five 180 days old Meishan pigs (A Chinese local pig breed). Total RNA extraction and first-strand cDNA synthesis for these tissue samples were performed using methods previously described (Liu et al., 2004). Briefly, total RNA was extracted using the TRIzol Reagent Total RNA Extraction Kit (GIBCO, USA). DNase I treatment was done before continuing with the first-strand cDNA synthesis. For each RNA sample, a single reverse transcription reaction was set up and then the efficiency of reverse transcription was checked on $1 \%$ agrose/EtBr gel.

\section{Isolation of pig NDP, CLN3 and NCF1 genes}

RT-PCR was performed to amplify complete coding sequences of these three pig genes using the cDNA obtained from the pooled tissues above. The $20 \mu 1$ reaction system was: $2.0 \mu 1 \mathrm{cDNA}, 2.0 \mu 12 \mathrm{mM}$ mixed dNTPs, $2.0 \mu 110 \times$ Taq DNA polymerase buffer, $1.2 \mu 125 \mathrm{mM} \mathrm{MgCl}_{2}, 1.0 \mu 110 \mathrm{mM}$ forward primer, $1.0 \mu 110$ $\mathrm{mM}$ reverse primer, 2.0 units of Taq DNA polymerase $(1 \mathrm{U} / 1 \mu \mathrm{l})$, and $9.8 \mu 1$ sterile water. The primers for porcine NDP gene isolation were designed based on the conserved coding sequences from human and mouse NDP genes and their highly homologues pig EST sequences (GeneBank numbers BE032856 and BX671963). Similarly, the primers for porcine CLN3 gene isolation were designed based on the conserved coding sequences from human and mouse CLN3 genes and their highly homologous pig EST sequences (Genbank numbers DB786839, BF078333, and DB813196). The primers for isolating the porcine NCF1 gene were designed based on the conserved coding sequences from human and mouse NCF1 genes and their highly homologues pig EST sequences (GenBank numbers BP440864 and DB820142). These primers were all designed to amplify the complete CDS (from start codon to the stop codon) for these three genes. These primer sequences and their annealing temperature for RT-PCR reaction are shown in Table 1.

The PCR products for porcine NDP, CLN3 and NCF1 cDNAs were then cloned into PMD18-T vector and sequenced bidirectionally with the commercial 
Table 1. Primers for porcine NDP, CLN3, NCF1, $\beta$-actin genes and their annealing temperatures

\begin{tabular}{llc}
\hline Gene & \multicolumn{1}{c}{ Primer sequence } & $\mathrm{Ta} /{ }^{\circ} \mathrm{C}$ \\
\hline NDP & $\begin{array}{l}\text { Forward: 5 - ATGAGAAATCATGTACTAG-3 } \\
\text { Reverse: 5 - TCAGGAGCTGCACTCCTC-3 }\end{array}$ & 52 \\
CLN3 & $\begin{array}{l}\text { Forward: 5' - ATGGGAGGCTGCGCGGGC-3' } \\
\text { Reverse: 5' - TCAGGAGAGGCGGCAGAG-3' }\end{array}$ & 56 \\
NCF1 & $\begin{array}{l}\text { Forward: 5' - ATGGGGGACCCCTTCATC-3' } \\
\text { Reverse: 5' - TCAGACAGCGGATGCCAG-3' }\end{array}$ & \multirow{2}{*}{58} \\
$\beta$-actin & $\begin{array}{l}\text { Forward: 5' - ACTGCCGCGTCCTCCTCCTC-3' } \\
\text { Reverse: 5'- CTCCTGCTTGCTGATCCACATC-3' }\end{array}$ & \multirow{2}{*}{55} \\
\hline
\end{tabular}

fluorometric method. At least five independent clones were sequenced for every gene.

RT-PCR for transcription profile

RT-PCR for transcription profile analyses were performed using the cDNA obtained from the specific tissues above as described by Liu and Xiong (2007). The housekeeping gene, $\beta$-actin was used as an internal control. The primers and annealing temperature for porcine $\beta$-actin gene (GeneBank number AY550069) amplification is shown in Table 1. The size of the beta-actin PCR fragment is 399bp. To ensure that no false positive PCR fragments were generated from pseudogenes in the contaminating genomic DNA, $\beta$-actin primers were derived from different exons in the same gene. The primers for porcine NDP, CLN3 and NCF1 gene which were used to perform the RT-PCR for tissue transcription profile analyses were the same as the primers used for amplification in RT-PCR above. The $25 \mu 1$ reaction system was: $2.0 \mu \mathrm{l}$ pooled cDNA of each tissue $(100 \mathrm{ng} / \mu \mathrm{l}), 2.5 \mu 12 \mathrm{mM}$ mixed dNTPs, 2.5 $\mu 110 \times$ Taq DNA polymerase buffer, $2.5 \mu 125 \mathrm{mM} \mathrm{MgCl}_{2}, 2.0 \mu 110 \mathrm{mM}$ forward primer, $2.0 \mu 110 \mathrm{mM}$ reverse primer, 2.0 units of Taq DNA polymerase $(1 \mathrm{U} / 1 \mu 1)$, and $9.5 \mu 1$ sterile water. The PCR program initially started with a $94^{\circ} \mathrm{C}$ denaturation for $4 \mathrm{~min}$, followed by 30 cycles of $94^{\circ} \mathrm{C} / 1 \mathrm{~min}, \mathrm{Ta}^{\circ} \mathrm{C}(\mathrm{Table} 1) / 1 \mathrm{~min}, 72^{\circ} \mathrm{C} / 1 \mathrm{~min}$, then $72^{\circ} \mathrm{C}$ extension for $10 \mathrm{~min}$, finally $4^{\circ} \mathrm{C}$ to terminate the reaction. Every PCR was repeated five times.

\section{Sequence analysis}

The gene analysis for cDNA sequence was conducted using GenScan software (http://genes.mit.edu/GENSCAN.html). The protein prediction and analysis were performed using the Conserved Domain Architecture Retrieval Tool of BLAST at the National Center for Biotechnology Information (NCBI) server (http://www. 
ncbi.nlm.nih.gov/BLAST) and the ClustalW software (http://align. genome.jp/). The theoretical isoelectric point $(\mathrm{pI})$ and molecular weight $(\mathrm{Mw})$ of proteins was computed using the Compute $\mathrm{pI} / \mathrm{Mw}$ Tool (http://www.expasy.org/ tools/pi_tool. html).

\section{RESULTS}

Isolation results for porcine NDP, CLN3 and NCF1 gene. Through RT-PCR with pooled tissue cDNAs, for porcine NDP, CLN3 and NCF1 gene, the resulting PCR products were 402bp, 1317bp and 1179bp (Figure 1).
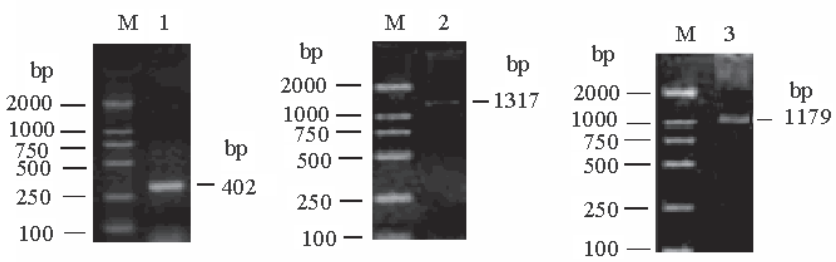

Figure 1. Isolation results for porcine NDP, CLN3 and NCF1. M, DL2000 DNA markers; 1, PCR product for porcine NDP gene; 2, PCR product for porcine CLN3 gene; 3, PCR product for porcine NCF1 gene

Sequence analysis. These cDNA nucleotide sequence analysis using the BLAST software revealed that these genes were not homologues to any of the known porcine genes and they were then deposited into the GenBank database (Accession number: EU287430, EU287431 and EU295556). The sequence prediction was carried out using the GenScan software and results showed that the 402bp, 1317bp and 1179bp cDNA sequences represented three single genes which encoded 133,438,392 amino acids, respectively. The theoretical isoelectric point $(\mathrm{pI})$ and molecular weight $(\mathrm{Mw})$ of these deduced proteins of these three pig genes were computed using the Compute $\mathrm{pI} / \mathrm{Mw}$ Tool. The pI of porcine NDP, CLN3 and NCF1 are 9.07, 5.94 and 9.25, respectively. The molecular weights of these three putative proteins are 14992.41, 47541.76 and 45291.63, respectively.

Further BLAST analysis of these proteins revealed that porcine NDP has high homology with the NDP of four species: bovine (98\%), human (96\%), crab-eating macaque (96\%) and mouse (95\%). The porcine CLN3 has high homology with the Batten disease protein (CLN3) of four species: human (90\%), crab-eating macaque $(90 \%), \operatorname{dog}(89 \%)$ and mouse $(83 \%)$. The porcine NCF1 has high homology with neutrophil cytosolic factor 1 (NCF1) of three species: bovine (87\%), human $(82 \%)$ and mouse $(79 \%)$ (Figures 2, 3, and 4). 
Pig

Bovine

Human_Crab-eating macaque Mouse

Pig
Bovine
Human_Crab-eating nacaque
Mouse

\section{Pig}

Bovine

Human_Crab-eating naceque Mouse

\author{
HRNHVLAASTSHLSLLALMGDTDSKTD SSFMM SD PFRCMRHHYWSISH

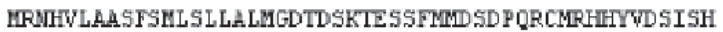 \\ HRKHVLAASFSMLSLLVIMGDTDSKTDSSF IMDSD PRRCMRHHYVSISH \\ HRNHVLALSISMLSLLAIMGDTDSKTD SSFLMDS--QRCMRHHYTDSISH

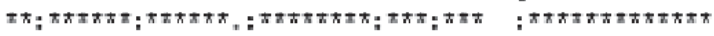 \\ PLYKC SSKMTL LARCEGHC SQASRSEP LVSFSTYLKOP FR' SCHCCRPOT \\ PLYKCSSKMUL LARCEGHCSOASRSEP LWSFSTYLKOP FRS SCFCCRPQT \\ PLYKC SSKATL LARCEGHC SQASRSEPLVSFSTVLROP FRS SCHCCRPOT \\ PLYKCSSKLWL LARCEGHCSOASRSEPLYSFSTWLKOP FRS SCHCCRPOT

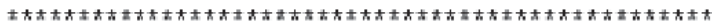

\section{SKLKALRLRCSGGURLTATYRYILSCHCEECSS SKLKALRLRCSGGYRLTATYRYILSCHCEECSS SKLKALRLRCSGGMRTATYRYILSCHCEECNS SKLKALRLRCSGGMRTATYRYILSCHCEECSS

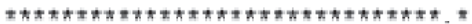

Figure 2. The alignment of the protein encoded by porcine NDP gene and other four kinds of NDP from bovine, mouse human and crab-eating macaque

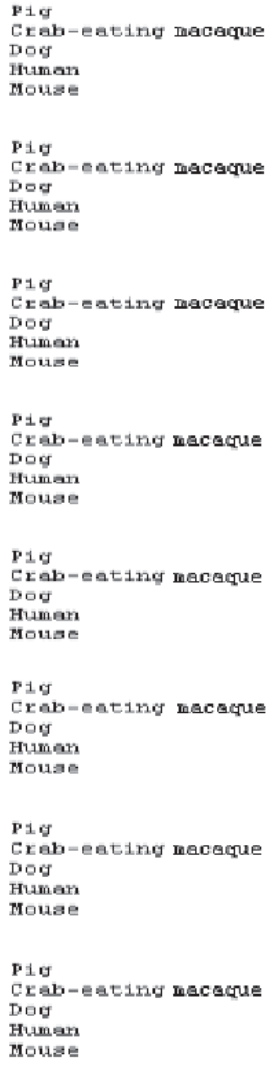

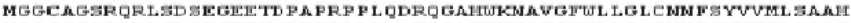
MGGCAGSRRRLSD SEGEETVPEPRL PL LDHO GAHTKNA WGFUL LGLCNNF\$ YVVML SAAH

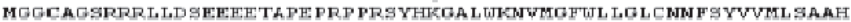

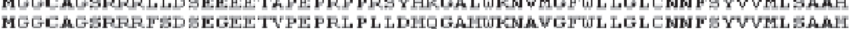
MGG SAGSTRR SED

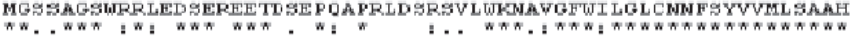

DIL SHORA P GNOSHVD PD PTPTPHNSTSRFD CN SVSTAAVL LADI LPTL I IKL LAPLGLH DIL SHERT SGND SHVD PGPAP I PHNS S SR PDCNS VSTAAVL LADIL PTLVIKL LAPIGLH

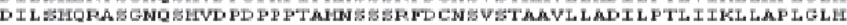

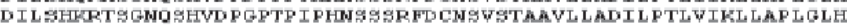

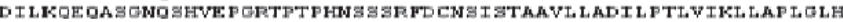
$\pi+$.

I L PYSPRVLTSGICAAGS FI IVAFSHSVATS LCGWV LAS IS SGLGEWTHLS LTS FYPRTW

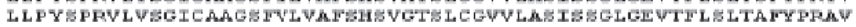

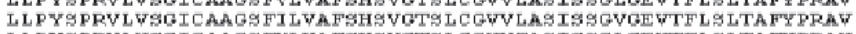
ILPYSPRVL WBGICAAGSTVWAFSH

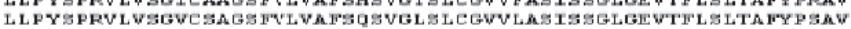

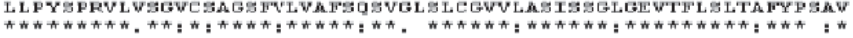

IङWW ECTGGACLLCALEYICLTOAGLSPQHTLLEMLGIPALKLASYTLLLTEPGEODPG

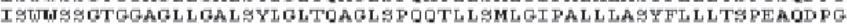
I I

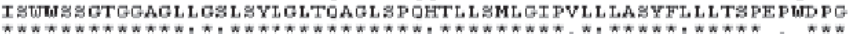

GEEEAETAARDP L INSEAPB LKPOSGSHL S L OERWTV FKOL LHYIWP LVLWYFAEYF IND

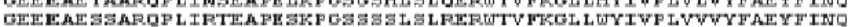

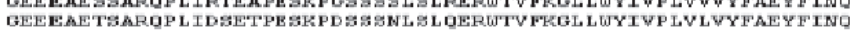

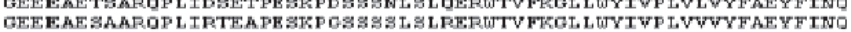

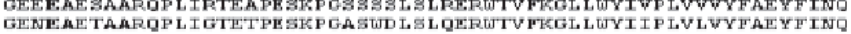

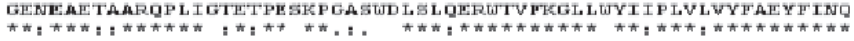

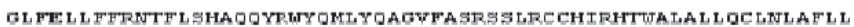

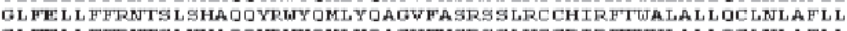

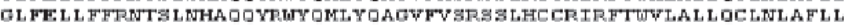

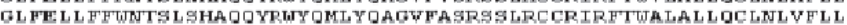
CL FE L L FFRNTS L SHAHE YRWY OML YOACWFA SRS S L OCCR IRHTWWLA L L DC LNLA L L

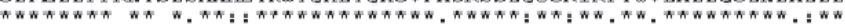

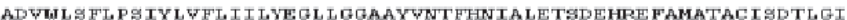

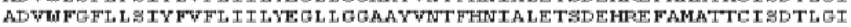

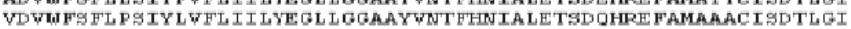
ADVU FGFL P IY L TFL I I IYEGL L GGAAYVNT FHNIALETSDEHRE FAMAATCISDTL GI ADWC LNFL P SIYLIFIIILFEGLLGGAAYVNTFHNIALETSDFHRE FAMEAACISDTLGI 类

BLIELLALPLHDFLCRL:

SLIOLLALPLHDFLCOL? BLIELLALPLHDFLCHL BLFELLALPLHEFLCOLS ML SEWLAL P LHD FLCHLP A\#

Figure 3. The alignment of the protein encoded by porcine CLN3 gene and other four kinds of CLN3 from crab-eating macaque, dog, human and mouse 
Pig

Eiovine

Humen

Mouse

Pig

Bovine

Human

Mouse

Pig

Bovire

Humen

Mouse

Pig

Bovine

Human

Mouse

Pig

Bovine

Huraen

Mouse

Pig

Eiovine

Human

Mouae

Pig

Bovime

Funan

House
MODP FIRHIALLGFERRFVPSQHYWTFLVKUQD LSEKLVYRRFTE IYE FHKTLKQMFP I MGDHF IRHI AL L GFEKRFV P SQHYTYMF L VKU QD L SEKVVYRRFTE IVE FHK. I LKEMF P I

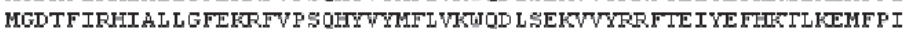
MGDTF IRHIALL LFEKRFIP SQHYYYMFLVKU QD L SEKVVYRKFTE IYE FHEMLKEMFP I

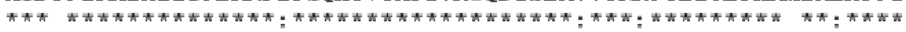

EAGD ITPENRIIPHL PAPRUFDGQRWAE SRDGTL SE XC SALMS LPVKI SRCPJHFLMFFEW EAGD INPENRI I PHL P A PRUYD GQRWAE SROGTL TEYCST LMS L PVKI SRC PJIL LN F FKW EAGAINPENR I IPHL PAPKUFD GQRASENROGTL TEYC STLM L PTKI SRC PJEL LD FFKW EAGE IHTENRVI PHL PAPRWFDGORAAE SROGTL TEYFWGLMGL PVKI SRC PJLL LD F FKW

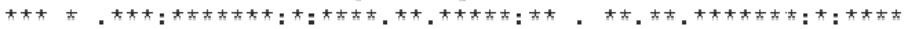

RPDD LKL P ADNQWKRPETY LMARD GFONJI AD IT GP I I IOTYRA IASYEKWSR:SEMT LATG RPDD LKL PTD SQVKKPETY LMPKD GKNNAAD ITEPIIL QTYRA I ADYEKESร รOMALATE

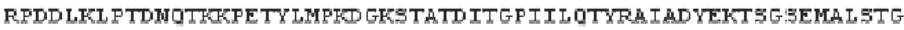
RPDD LKL PTD SQAKKKPETY LVPKD GKNNVAD ITGPII L QTYRA I ADYEKS SGTEMTVATG

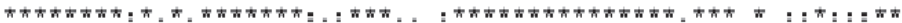

DVNDWEKNENGUT FCOMKTKRGWVP ASYLEPLD D PDE SED PE PNYEGE PYWTIKSYTAL

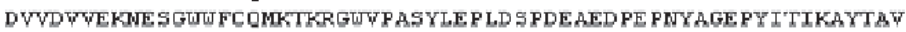
DVVEVWKSE SGUUT FCDMRAKR GUI I AS FLE P LD S PDETED PE PNYAGE PTV ALIKAYTAV

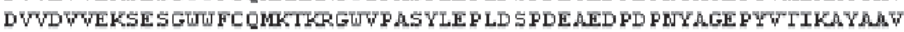

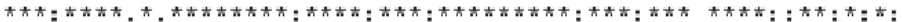

LEDEVSLEQGETIEWIHKL LD GUTWTFKED ITGYFP STYL LKA GODVAEAQSIKIKSRGAP

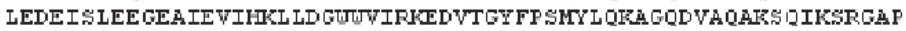
EGDEW SL LE GEAWE THKL LD GUWTIRKDDVTGYFP SMY L QKS GQDVSOAOR.IIKR-GAP EEDEM L SE GEA IE W IHKL LD GUTWWRKGD ITGYFP SKX L OKA GEE ITOAORIDIRGRGAP $\pi$ : $\pi$ : :

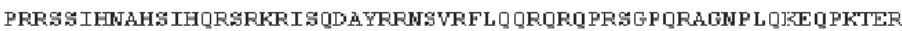
PRRSSIRNAHSTHQRSRKRL SQDTYRRWSVR FMQQRRHORPE P QRSRSALRE DQQPKTER PRRSI IFNAHS IHORSRKR L SODA YFFWSVRFL Q QRRROARP GPQS P GS P LEJEER-OTOR PRRSTIRNAQSTHQRSRKRL SQDTYRRNSVRFLQQRRRP GRPGQLSTDG--TIKDNPSTPR

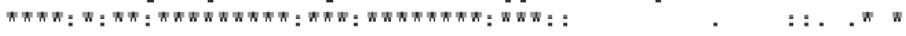

PKPQPAVPPRPSADLILHRCSE STKRELASAV PKPQPAVPPRPSADLILHRCSESTKRKLARAV SKPOPAVPPRFSADLILNRCSESTKRKLASAV VKPQPAVPPRPSSDLILHRCTESTKRIZLTSAV

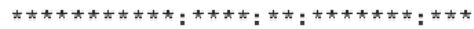

Figure 4. The alignment of the protein encoded by porcine NCF1 gene and other three kinds of NCF1 from bovine, human and mouse

Based on the results of the alignment of NDP, CLN3 and NCF1, phylogenetic trees were constructed using the Dendrogram procedure of ClustalW software (http://align.genome.jp/), as shown in Figures 5-7.

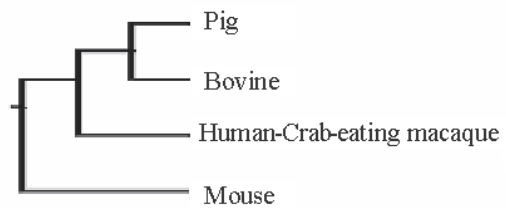

Figure 5. The phylogenetic tree for five kinds of NDP from pig, bovine, human, crab-eating macaque and mouse 


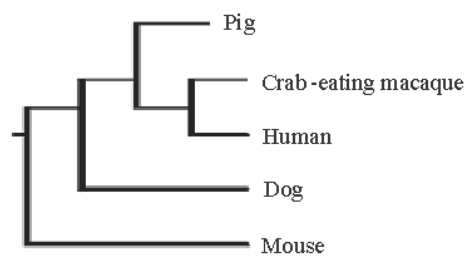

Figure 6. The phylogenetic tree for five kinds of CLN3 from pig, crab-eating macaque, human, dog and mouse

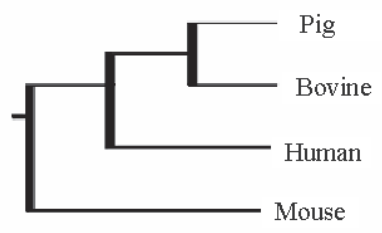

Figure 7. The phylogenetic tree for four kinds of NCF1 from pig, bovine, human and mouse

The phylogenetic tree analysis revealed that the porcine NDP and NCF1 have closer genetic relationships with the bovine NDP and NCF1, while the pig CLN3 has a closer genetic relationship with the human and crab-eating macaque CLN3.

Tissue transcription profile. Tissue transcription profile analysis revealed that, compared to the expression of pig $\beta$-actin gene, pig NDP gene was expressed in muscle, spleen, brain, lung but not expressed in kidney, liver, backfat and pancreas. Pig CLN3 and NCF1 genes were generally expressed in brain, kidney, liver, muscle, backfat, lung, spleen and pancreas (Figure 8).

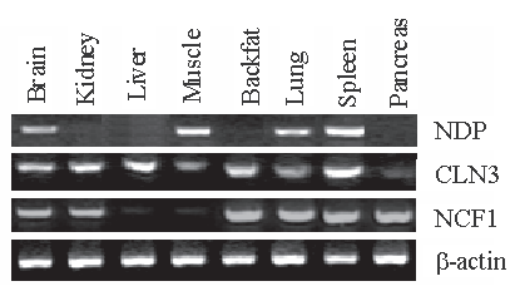

Figure 8. Tissue transcription profile of pig NDP, CLN3 and NCF1 gene. The $\beta$-actin expression is the internal control 


\section{DISCUSSION}

Dickinson et al. (2006) had reported two mutations (Leu103Val, His43Arg) within the coding region of the NDP gene: one associated with severe disease phenotypes of Norrie disease and the other with X-linked familial exudative vitreoretinopathy. Similarly, to the CLN3 gene, Zhong et al. (1998) had reported that a missense mutation of glutamic acid (E) to lysine (K) at position 295 in the human CLN3 protein has been implicated in Juvenile neuronal ceroid lipofuscinosis (Batten disease). One particular mutation in NCF1, a GT deletion in exon 2 had been identified to be associated with $>97 \%$ cases of human chronic granulomatous disease (Roos et al., 2006). Therefore, isolation of the encoding regions of the porcine NDP, CLN3 and NCF1 genes is utmost important to detect these three kinds of diseases.

The present study cloned and analysed the cDNA sequence for three porcine genes whose human homologues are associated with mutation diseases. The data show that the porcine genes are highly similar to the human genes, making the pig a potential non-primate model for studying these genes. From the alignment analyses of the NDP, CLN3 and NCF1 proteins there were no differences found at the above loci in human, pig, mouse and other mammals detected, but many more other amino acid differences were found in these three kinds of proteins. These implied that in the future research of these three genes, we should pay more attentions to that if these amino acid differences and above reported human mutations would also happen in pig and the potential associations of them with the pig diseases.

From the phylogenetic tree analysis show that pig NDP, CLN3 and NCF1 genes have much closer relationships with human than mouse. This implies that the pig will be more suitable as a model animal to study these three kinds of human mutation diseases. In other words, theoretically, pig is also a kind of susceptive animal to these diseases.

We also noticed that human and mouse NDP, CLN3 and NCF1 genes had been found to be expressed in most of tissues (http://www.ncbi.nlm.nih.gov/ UniGene). From the tissue transcription profile analysis in our experiment it can be seen that CLN3 and NCF1 genes were generally expressed in most of tissues, but to porcine NDP gene, there were no expression in some tissues detected. This needs to study furtherly.

In conclusion, we first isolated the pig NDP, CLN3 and NCF1 genes and performed necessary sequence analysis and tissue transcription profile analysis. This established the primary foundation for further research on these three pig genes. 


\section{REFERENCES}

Adams H.R., Kwon J., Marshall F.J., de Blieck E.A., Pearce D.A., Mink J.W., 2007. Neuropsychological symptoms of juvenile-onset batten disease: experiences from 2 studies. J. Child Neurol. 22, 621-627

Battinelli E.M., Boyd Y., Craig I.W., Breakefield X.O., Chen Z.Y., 1996. Characterization and mapping of the mouse NDP (Norrie disease) locus (Ndp). Mamm. Genome 7, 93-97

Dickinson J.L., Sale M.M., Passmore A., Fitzgerald L.M., Wheatley C.M., Burdon K.P., Craig J.E., Tengtrisorn S., Carden S.M., Maclean H., Mackey D.A., 2006. Mutations in the NDP gene: contribution to Norrie disease, familial exudative vitreoretinopathy and retinopathy of prematurity. Clin. Exp. Ophthalmol. 34, 633-634

Eliason S.L., Stein C.S., Mao Q., Tecedor L., Ding S.L., Gaines D.M., Davidson B.L., 2007. A knock-in reporter model of Batten disease. J. Neurosci. 27, 9826-9834

El Kares R., Barbouche M.R., Elloumi-Zghal H. et al., 2006. Genetic and mutational heterogeneity of autosomal recessive chronic granulomatous disease in Tunisia. J. Hum. Genet. 51, 887-895

Hardison R.C., 2003.Comparative genomics. PLoS Biol. 1, E58 (Abstr.)

Kishida K.T., Hoeffer C.A., Hu D., Pao M., Holland S.M., Klann E., 2006. Synaptic plasticity deficits and mild memory impairments in mouse models of chronic granulomatous disease. Mol. Cell Biol. 26, 5908-5920

Köker M.Y., Sanal O., De Boer M., Tezcan I., Metin A., Ersoy F., Roos D., 2007. Mutations of chronic granulomatous disease in Turkish families. Eur. J. Clin. Invest. 37, 589-595

Kovács A.D., Pearce D.A., 2008. Attenuation of AMPA receptor activity improves motor skills in a mouse model of juvenile Batten disease. Exp. Neurol. 209, 288-291

Lev D., Weigl Y., Hasan M., Gak E., Davidovich M., Vinkler C., Leshinsky-Silver E., Lerman-Sagie T., Watemberg N., 2007. A novel missense mutation in the NDP gene in a child with Norrie disease and severe neurological involvement including infantile spasms. Amer. J. Med. Genet. A $143,921-924$

Liu G.Y., Xiong Y.Z., 2007.Isolation, sequence analysis and expression profile of a novel porcine gene, NIP7, differentially expressed in the Longissimus dorsi muscle tissues from Meishan, Meishan x Large White cross and Large White pigs. Mol. Biol. Rep. 344, 213-219

Liu Y.G., Xiong Y.Z., Deng C.Y., Zuo B., Zhang J.H., 2004. Comparison of gene expression patterns in Longissimus dorsi of pigs between the high-parent heterosis cross combination Landrace $\times$ Large White and the mid-parent heterosis cross combination Large White $\times$ Meishan. Asian-Austr. J. Anim. Sci. 17, 1192-1196

Luhmann U.F., Meunier D., Shi W., Lüttges A., Pfarrer C., Fundele R., Berger W., 2005. Fetal loss in homozygous mutant Norrie disease mice: a new role of Norrin in reproduction. Genesis 42, 253-262

Lunney J.K., 2007. Advances in swine biomedical model genomics. Int. J. Biol. Sci. 3, 179-184

Rakheja D., Narayan S.B., Bennett M.J., 2007. Juvenile neuronal ceroid-lipofuscinosis (Batten disease): a brief review and update. Curr. Mol. Med. 7, 603-608

Roos D., de Boer M., Köker M.Y., Dekker J., Singh-Gupta V., Ahlin A., Palmblad J., Sanal O., Kurenko-Deptuch M., Jolles S., Wolach B., 2006. Chronic granulomatous disease caused by mutations other than the common GT deletion in NCF1, the gene encoding the p47phox component of the phagocyte NADPH oxidase. Hum. Mutat. 27, 1218-1229

Rothschild M.F., Plastow G.S., 2008. Impact of genomics on animal agriculture and opportunities for animal health.Trends Biotech. 26, 21-25

Wollmann G., Lenzner S., Berger W., Rosenthal R., Karl M.O., Strauss O., 2006. Voltage-dependent ion channels in the mouse RPE: comparison with Norrie disease mice. Vision Res. 46, 688-698

Zhong N., Wisniewski K.E., Kaczmarski A.L., Ju W., Xu W.M., Xu W.W., Mclendon L., Liu B., Kaczmarski W., Sklower Brooks S.S., Brown W.T., 1998. Molecular screening of Batten disease: identification of a missense mutation (E295K) in the CLN3 gene. Hum. Genet. 102, 57-62 